\title{
1 Mountain stoneflies may tolerate warming streams: evidence from organismal \\ 2 physiology and gene expression
}

4 Scott Hotaling ${ }^{1, *}$, Alisha A. Shah ${ }^{2, \star}$, Kerry L. McGowan ${ }^{1}$, Lusha M. Tronstad ${ }^{3}$, J. Joseph

5 Giersch $^{4}$, Debra S. Finn ${ }^{5}$, H. Arthur Woods ${ }^{2}$, Michael E. Dillon ${ }^{6, a}$, and Joanna L. Kelley ${ }^{1, a}$

7 Affiliations:

$8{ }^{1}$ School of Biological Sciences, Washington State University, Pullman, WA, USA

$9{ }^{2}$ Division of Biological Sciences, University of Montana, Missoula, MT, USA

$10{ }^{3}$ Wyoming Natural Diversity Database, University of Wyoming, Laramie, WY, USA

$11{ }^{4}$ U.S. Geological Survey, Northern Rocky Mountain Science Center, West Glacier, MT, USA

$12{ }^{5}$ Department of Biology, Missouri State University, Springfield, MO, USA

$13{ }^{6}$ Department of Zoology and Physiology and Program in Ecology, University of Wyoming,

14 Laramie, WY, USA

15 * Contributed equally

16 a Co-supervised research

Correspondence:

Scott Hotaling, School of Biological Sciences, Washington State University, Pullman, WA, 99164, USA; Email: scott.hotaling@wsu.edu; Phone: (828) 507-9950; ORCID: 0000-0002-59650986

Alisha A. Shah, Division of Biological Sciences, University of Montana, Missoula, MT, 59812, USA, Email: alisha.shah@mso.umt.edu; Phone: (512) 694-7532; ORCID: 0000-0002-84547905

Running head: Thermal tolerance of mountain stoneflies

Keywords: critical thermal maximum; RNAseq; Plecoptera; alpine streams; thermal tolerance; climate change; Lednia tumana; endangered species; glacier biology

\section{Abstract:}

33 Rapid glacier recession is altering the physical conditions of headwater streams. Stream

34 temperatures are predicted to rise and become increasingly variable, putting entire meltwater- 
associated biological communities at risk of extinction. Thus, there is a pressing need to understand how thermal stress affects mountain stream insects, particularly where glaciers are likely to vanish on contemporary timescales. In this study, we tested the critical thermal maximum ( $\mathrm{CT}_{\mathrm{MAX}}$ ) of stonefly nymphs representing multiple species and a range of thermal regimes in the high Rocky Mountains, USA. We then collected RNA-sequencing data to assess how organismal thermal stress translated to the cellular level. Our focal species included the meltwater stonefly, Lednia tumana, which was recently listed under the U.S. Endangered Species Act due to climate-induced habitat loss. For all study species, critical thermal maxima $\left(\mathrm{CT}_{\text {MAX }}>20^{\circ} \mathrm{C}\right)$ far exceeded the stream temperatures mountain stoneflies experience $\left(<10^{\circ} \mathrm{C}\right)$. Moreover, while evidence for a cellular stress response was present, we also observed constitutive expression of genes encoding proteins known to underlie thermal stress (i.e., heat shock proteins) even at low temperatures that reflected natural conditions. We show that highelevation aquatic insects may not be physiologically threatened by short-term exposure to warm temperatures and that longer term physiological responses or biotic factors (e.g., competition) may better explain their extreme distributions.

\section{Introduction:}

Predicting how species will respond to climate change is a central goal of contemporary ecology (Araújo \& New, 2007, Urban et al., 2016). This goal is difficult to achieve, however,

54 because at a minimum it requires knowledge of extant distributions, physiological limits, and

55 future conditions in relevant habitats. Mountain streams around the world are being transformed

56 by climate change, primarily through rapid recession of glaciers and perennial snowfields

57 (Hotaling et al., 2017). Warmer air temperatures are predicted to cause loss of permanent snow

58 and ice, drive generally higher, more variable stream temperatures, and eventually lower flows

59 in meltwater-dominated catchments (Huss \& Hock, 2018, Jones et al., 2014). Rapid

60 contemporary warming has already been observed in the European Alps, with streams warming

61 at a mean rate of $2.5^{\circ} \mathrm{C}$ per decade (Niedrist \& Füreder, 2020). Expected ecological responses

62 include a reduction of biodiversity in headwater streams across multiple levels of biological

63 organization and taxonomic groups (Bálint et al., 2011, Finn et al., 2013, Giersch et al., 2017,

64 Hotaling et al., 2019a, Jordan et al., 2016). Considerable attention has been devoted to

65 potential losses of aquatic insect diversity (e.g., Jacobsen et al., 2012). However, the specific

66 mechanisms underlying physiological limits in alpine stream insects remain unknown. This

67 knowledge gap is particularly important in light of the widely held assumption that aquatic

68 insects living at high-elevations are cold-adapted stenotherms that will not tolerate warming 
streams (Giersch et al., 2015, Jacobsen et al., 2012). Recent evidence that the thermal maxima of high-elevation stream taxa can exceed maximum water temperatures (e.g., Shah et al., 2017b), that spring-dwelling cold stenotherms exhibit little variability in heat shock protein (HSP) expression across temperatures (e.g., Ebner et al., 2019), and that meltwater-associated invertebrate communities persist despite widespread deglaciation (Muhlfeld et al., 2020) all challenge this assumption, raising new questions about whether climate warming directly threatens headwater biodiversity. To better understand the degree to which headwater species can tolerate warming, links between relevant traits at the organismal (thermal stress) and cellular (e.g., gene expression) level are needed.

As ectotherms, insect body temperatures depend strongly on their external environment. Insects are therefore threatened by rising global temperatures, and recent studies have documented declines in their diversity (Lister \& Garcia, 2018, Sánchez-Bayo \& Wyckhuys, 2019). The effects of temperature on ectotherm performance and survival, however, are complex. Ectotherms may respond to stressful temperatures through plasticity or acclimatization (Seebacher et al., 2015), the evolution of higher thermal limits (Angilletta Jr et al., 2007), or behavioral thermoregulation (Kearney et al., 2009). Temperature can also affect organismal distributions indirectly. For instance, changing temperatures can alter ratios of oxygen supply and demand (Pörtner et al., 2007, Verberk et al., 2016b). Extreme temperatures can also provide natural buffering against invasions by competitors or predators (Isaak et al., 2015). Thus, temperature likely shapes both the evolution of aquatic insect physiology as well as local networks of biotic interactions (Shah et al., 2020). To understand the relationship between temperature and ectotherm tolerance, trait-based approaches (e.g., measuring upper thermal tolerance) can be informative. However, a focus on physiological traits at the whole-organism level may overlook other key aspects of a species' potential for response, perhaps limiting predictions of whether species can evolve in response to changing thermal regimes (Chown et al., 2010) or tolerate them in situ via plasticity. Thus, there is a need to connect traits from cellular to organismal levels and consider findings holistically.

Due to the high heat capacity of water, stream temperatures are less thermally variable

97 than air. However, a surprising amount of variation still exists in streams due to many factors,

98 including latitude, elevation, flow, and canopy cover (Shah et al., 2017b). At high-elevations, an

99 additional factor-the primary source of water input-plays an outsized role in dictating thermal

100 variation downstream (Hotaling et al., 2017). High-elevation freshwaters are fed by four major

101 hydrological sources: glaciers, snowfields, groundwater aquifers, and subterranean ice (Hotaling

102 et al., 2019a, Tronstad et al., In press, Ward, 1994). Glaciers and subterranean ice (e.g., rock 
103 glaciers) promote near constant, extremely cold conditions (i.e., less than $3^{\circ} \mathrm{C}$ year-round)

104 whereas snowmelt- and groundwater-fed streams are warmer and often more thermally variable

105 (Hotaling et al., 2019a, Tronstad et al., In press). However, these general thermal "rules" apply

106 only in close proximity to a primary source. Patterns can change dramatically downstream as

107 flows are altered (e.g., pooling into a high-elevation pond) and sources mix (e.g., a warmer

108 groundwater-fed stream flows into a glacier-fed stream). Resident aquatic taxa therefore

109 experience vastly variable thermal conditions both within and across their life stages. With

110 extensive thermal variation over small geographic scales and abundant, putatively cold-adapted

111 resident invertebrates, high-elevation waters provide an ideal, natural model for testing

112 hypotheses of physiological limits in a framework relevant to global change predictions.

113 In this study, we investigated gene expression as a function of tolerance to heat stress

114 for stonefly nymphs collected from high-elevation streams in the northern Rocky Mountains. We

115 focused on three taxa-Lednia tetonica, Lednia tumana, and Zapada sp.—all of which have

116 habitat distributions closely aligned with cold, meltwater stream conditions. Lednia tumana was

117 recently listed under the U.S. Endangered Species Act due to climate-induced habitat loss (U.S.

118 Fish \& Wildlife Service, 2019). To test tolerance to heat stress at the organism level, we

119 measured the critical thermal maximum ( $\mathrm{CT}_{\mathrm{MAX}}$ ), a widely used metric for comparing thermal

120 tolerance among animals (Healy et al., 2018). We specifically addressed three overarching

121 questions: (1) Does natural thermal variation in stream temperature predict mountain stonefly

$122 \mathrm{CT}_{\text {MAX }}$ ? (2) Do high-elevation stoneflies mount cellular stress responses when subjected to heat

123 stress? And, if so, which genes are involved? (3) Is there a link between habitat conditions,

124 organismal limits, and underlying gene expression? Following Shah et al. (2017b), we expected

125 nymphs from streams with higher maximum temperatures to have correspondingly higher

126 values of $\mathrm{CT}_{\text {MAX }}$. We also expected to observe a signal of cellular stress with genes typical of

127 heat stress responses (e.g., HSPs) upregulated. Finally, we expected nymphs that naturally

128 experience higher temperatures to exhibit a correspondingly muted cellular stress response.

129 Collectively, our study sheds new light on thermal stress in high-elevation stream insects and

130 contributes new perspective to a pressing challenge for the field: clarifying whether species

131 living in cold headwaters are as sensitive to warming temperatures as their extreme distributions

132 suggest. 
Table 1. Environmental variation, mountain range, and habitat types included in this study. GNP: Glacier National Park, Montana. GRTE: Teton Range, Wyoming. TMAX: the maximum temperature observed, $T_{\text {RANGE}}$ : the difference between the maximum and minimum temperatures observed, and $\mathrm{T}_{\mathrm{MEAN}}$ : the mean temperature observed. All temperature data are in degrees Celsius. SPC: specific conductivity $\left(\mu \mathrm{S} \mathrm{cm}^{-1}\right)$, PI: Pfankuch Index, a measure of stream channel stability (higher values correspond to a less stable streambed). Temperatures were measured on a representative day in late July 2019 for all sites except Lunch Creek (data from late July 2014). See Table S1 for specific dates of temperature data collection.

\begin{tabular}{lllllllll}
\hline Population & Range & Taxa & Type & T $_{\text {MAX }}$ & T $_{\text {RANGE }}$ & T MEAN $_{\text {SPC }}$ & PI \\
\hline Lunch Creek & GNP & L. tumana & Snowmelt & 9.9 & 5.7 & 6.2 & 40.7 & 25 \\
Wind Cave & GRTE & Zapada sp. & Icy seep & 3.2 & 0.5 & 2.8 & 101.1 & 18 \\
Mt. St. John & GRTE & L. tetonica & Icy seep & 4.6 & 2.2 & 3.0 & 25.0 & 34 \\
Cloudveil Dome & GRTE & L. tetonica & Glacier-fed & 2.1 & 0.3 & 2.0 & 4.1 & 32 \\
Skillet Glacier & GRTE & L. tetonica & Glacier-fed & 7.1 & 4.4 & 4.4 & 3.1 & 34 \\
Tetonica Pond $^{\mathrm{a}}$ & GRTE & L. tetonica & Pond & 4.9 & 2.3 & 3.1 & 29.3 & $\mathrm{n} / \mathrm{a}$ \\
\hline
\end{tabular}

${ }^{a}$ Named by the authors. Does not reflect official conventions.

\section{Materials and Methods:}

\section{Specimen collection}

During the summer of 2018 (29 July-6 August), we collected late-instar stonefly nymphs representing at least three species (Lednia tetonica, Lednia tumana, and Zapada sp.; Family Nemouridae) from six streams in Glacier National Park (GNP), Montana, and Grand Teton National Park and the surrounding region (GRTE), Wyoming, USA (Figure 1; Tables 1, S1). We selected a later summer timepoint because it represents the warmest stream temperatures nymphs experience before emerging in August. Also, given the acclimation capacity of $\mathrm{CT}_{\text {MAX }}$ in temperate aquatic insects (Shah et al., 2017a), we measured $\mathrm{CT}_{\text {MAX }}$ during this period because it is also when we expected $\mathrm{CT}_{\text {MAX }}$ to be highest. Specimens were collected by turning over rocks and gently transferring nymphs to a small tray filled with streamwater. Nymphs were brought to the laboratory as quickly as possible in $1 \mathrm{~L}$ Whirl-Pak bags (Nasco) filled with streamwater surrounded by snow or ice. Species were identified based on morphological variation following previous studies (e.g., Giersch et al., 2017). Unlike Lednia, multiple Zapada species can be present in the same stream and previous genetic data has indicated the potential for cryptic diversity in the group (Hotaling et al., 2019b). Therefore, we cannot exclude the possibility of more than one species of Zapada in the Wind Cave population and thus only identified Zapada to genus (Table 1). 

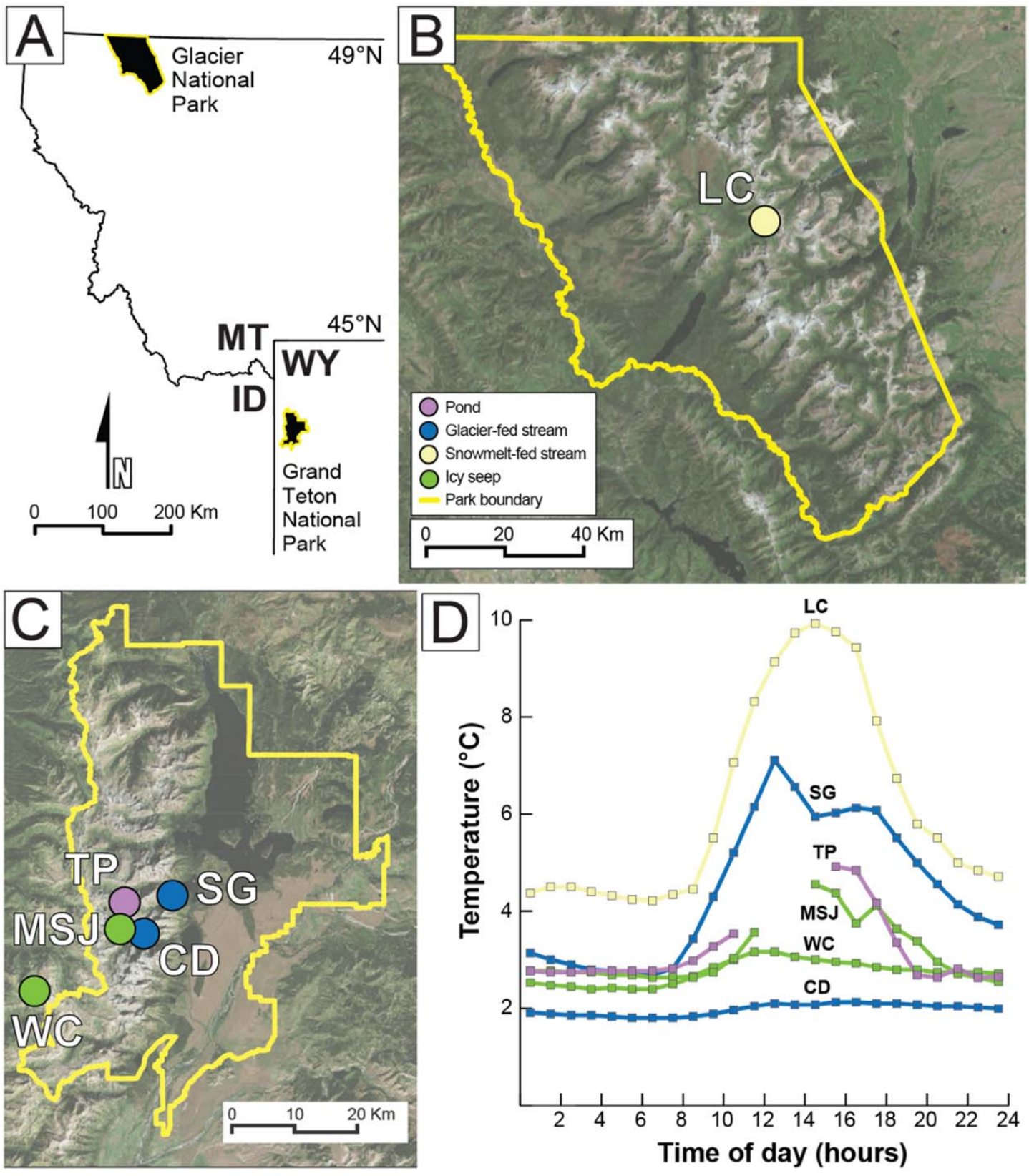

Figure 1. (A) The region of the Rocky Mountains where this study was conducted including (B) Glacier National Park, MT and (C) Grand Teton National Park, WY and the surrounding region. (D) A thermograph of hourly temperatures for each study site in late July. Site acronyms (top to bottom): Lunch Creek (LC), Skillet Glacier (SG), Tetonica Pond (TP), Mt. St. John (MSJ), Wind Cave (WC), and Cloudveil Dome (CD). A complete 24-hour thermograph is not shown for MSJ and TP because only 21 and 19 hours of continuous data were recorded for those sites, respectively. More extensive thermal data are provided in Figure S1. 


\section{Environmental data and aquatic habitat classifications}

For each study stream, we measured temperature by placing in situ HOBO loggers (Temperature Pro v2, Onset Computer Corporation) that recorded temperature hourly. Lengths of logger deployments ranged from less than 24 hours (Mt. St. John, Tetonica Pond) to several days (Cloudveil Dome) or a full year (Lunch Creek, Skillet Glacier, Wind Cave). Using these data, we constructed a one-day thermograph for each site based on a representative day in late July (exact dates provided in Table $S 1$ ) and estimated the highest ( $T_{\text {MAX }}$ ), range ( $T_{\text {RANGE }}$ ), and mean ( $\left.\mathrm{T}_{\text {MEAN }}\right)$ temperatures for that day. For two sites with more than one year of temperature data (Wind Cave: 2016, 2019; Lunch Creek: 2012, 2013, 2014), we compared multiple complete thermographs for July to ensure that our results were not biased by an unusual year- or dayspecific pattern (Figure S1). We also collected two additional environmental variables to inform our habitat classifications (see below): specific conductivity (SPC), measured with a YSI Professional ProPlus multiparameter probe which was calibrated at the trailhead before each sampling trip, and stream channel stability, calculated via a modified version of the Pfankuch Index (PI), a standard metric for assessing channel stability in mountain systems that integrates five key physical characteristics of the stream into a single value (Peckarsky et al., 2014). We classified sites into habitat types following previous studies (Giersch et al., 2017, Hotaling et al., 2019a, Tronstad et al., In press). Briefly, we incorporated a site's primary hydrological source, environmental variation, and geomorphology, to group them into one of four habitat types: streams fed by a surface glacier ("glacier-fed"), a perennial snowfield ("snowmelt-fed"), emanating from subterranean ice (e.g., rock glaciers, "icy seep"), or slowflowing, alpine ponds ("pond"). We categorized a stream as glacier-fed if it had a named glacier upstream and an extremely unstable streambed $(\mathrm{PI}>30)$. Any other streams fed by perennial surface ice and snow were categorized as snowmelt-fed. We classified streams as icy seeps if we observed evidence of a subterranean ice source (e.g., lobes of a rock glacier), they were extremely cold (e.g., $\mathrm{T}_{\mathrm{MAX}}<5^{\circ} \mathrm{C}$ ), and had high conductivity (SPC > 50; Hotaling et al., 2019a). Ponds were identified by their low-angle profile and the presence of standing water. 
Table 2. Morphological and physiological data included in this study. Holding: time (hours) that specimens were held at $3^{\circ} \mathrm{C}$ with no access to food before testing. $N$ : sample size for each population. Mean body lengths were used as a proxy for mass and are reported in millimeters with standard errors. RNAseq: sample sizes for RNA sequencing for treatment ( $\left.T ; \mathrm{CT}_{\mathrm{MAX}}\right)$ and control $\left(\mathrm{C}\right.$; held at $\left.3^{\circ} \mathrm{C}\right)$ specimens. Mean $\mathrm{CT}_{\mathrm{MAX}}$ is given in degrees Celsius.

\begin{tabular}{|c|c|c|c|c|c|c|}
\hline Population & Taxon & Length & Holding & $N$ & Mean $\mathrm{CT}_{\text {MAX }}$ & RNAseq $(N)$ \\
\hline Lunch Creek & L. tumana & $4.9 \pm 0.5$ & 72 & 24 & 28.7 & $3 \mathrm{~T} / 3 \mathrm{C}$ \\
\hline Wind Cave & Zapada sp. & $4.4 \pm 0.6$ & 48 & 23 & 25.9 & -- \\
\hline Mt. St. John & L. tetonica & $5.6 \pm 0.7$ & 12 & 24 & 26.6 & 3T / 3C \\
\hline Cloudveil Dome & L. tetonica & $4.5 \pm 0.5$ & 12 & 23 & 26.1 & -- \\
\hline Skillet Glacier & L. tetonica & $5.6 \pm 0.4$ & 12 & 17 & 28.6 & -- \\
\hline Tetonica Pond & L. tetonica & $4.6 \pm 0.6$ & 12 & 23 & 28.6 & $3 T / 3 C$ \\
\hline
\end{tabular}

\section{Measuring critical thermal maxima $\left(C T_{M A X}\right)$}

Nymphs were brought into the laboratory as quickly as possible (typically less than 12 hours after collection) and transferred to holding chambers in 150-quart coolers filled with water from a nearby stream (Pacific Creek: $43.9036^{\circ},-110.5892^{\circ}$ ). We used aquarium chilling units $\left(1 / 10 \mathrm{HP}\right.$, Coralife) to maintain the holding baths at $\sim 3^{\circ} \mathrm{C}$ (Figure S2). Each holding chamber contained 12 nymphs in a $\sim 2$ plastic container immersed in the bath such that both water and nymphs were isolated from the rest of the system. We included plastic mesh in each chamber to give nymphs substrate to cling to. We maintained high levels of water flow and dissolved oxygen by air stone bubbling in each chamber. Nymphs had no access to food during the holding period to ensure they were tested in a fasting state (i.e., after available food had been digested, absorbed, and cleared from the digestive tract). All nymphs were held in these conditions for at least $\sim 12$ hours before testing (Table 2).

We measured $\mathrm{CT}_{\mathrm{MAX}}$, a non-lethal temperature at which nymph locomotor function becomes disorganized. We placed up to 12 nymphs into mesh chambers (one individual per chamber) in a water bath held at $3^{\circ} \mathrm{C}$. Because warming is the most obvious effect of climate change in high-mountain streams, we chose to only vary temperature, while maintaining natural flow and oxygenation with air pumps. Four thermo-electric cooling (TEC) plates attached to a temperature controller were used to increase temperature at $\sim 0.25^{\circ} \mathrm{C}$ per minute. We recorded $\mathrm{CT}_{\text {MAX }}$ when an individual nymph could no longer right itself after being turned onto its back (Videos S1-S2). After a nymph reached its $\mathrm{CT}_{\mathrm{MAX}}$, we immediately transferred it to an $8^{\circ} \mathrm{C}$ bath for recovery and assessed survival by monitoring nymphs until they resumed normal movement. Nymphs were later preserved in $~ 95 \%$ ethanol. We measured body length to the nearest $1 / 4 \mathrm{~mm}$ using a dissecting microscope and a millimeter grid attached to the base of the microscope. A 
subset of nymphs were flash frozen at either their $\mathrm{CT}_{\mathrm{MAX}}$ or holding temperature for RNA sequencing (RNAseq).

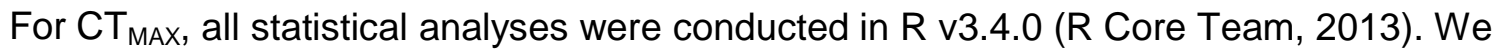
focused our main analysis on $L$. tetonica because we had data for multiple populations. We first analyzed the effect of body size (length) and acclimation period on $\mathrm{CT}_{\mathrm{MAX}}$ with linear models.

233 Because body size was not a significant predictor of $\mathrm{CT}_{\text {MAX }}$ (see Results), our final linear models assessing the effect of maximum stream temperature ( $\mathrm{T}_{\mathrm{MAX}}$ ) on $\mathrm{CT}_{\mathrm{MAX}}$ included only $\mathrm{T}_{\mathrm{MAX}}$ as the predictor variable. We also assessed the effect of $\mathrm{T}_{\mathrm{MAX}}$ on $\mathrm{CT}_{\mathrm{MAX}}$ in a second, broader analysis which included the two populations of L. tumana and Zapada sp. While valuable, this 'allspecies' analysis cannot be used to determine if $\mathrm{CT}_{\text {MAX }}$ varies among species or if the variation we observed is due to population-level differences because we lacked replicates for $L$. tumana and Zapada sp.

\section{RNA sequencing}

During the thermal tolerance experiment, a subset of individuals from three populations and both Lednia species (Lunch Creek, L. tumana; Mt. St. John and Tetonica Pond, L. tetonica;

244 Figure 1A, Table 2) were sampled for RNAseq. Nymphs at their CT $_{\text {MAX (treatment) and others }}$ that remained at the holding temperature (control) were flash frozen in liquid nitrogen. We sampled three treatment and three control nymphs for each population ( $N=18$ total; Table 2). Samples were stored in liquid nitrogen until they were transferred to a $-80^{\circ}$ freezer. We extracted total RNA from entire nymphs following the NucleoSpin RNA (Macherey-Nagel Inc.) protocol. For extraction, specimens were re-flash frozen with liquid nitrogen in a $1.5 \mathrm{~mL}$ microcentrifuge tube and ground into a fine powder with a sterilized pestle. We quantified RNA with a Qubit 2.0 fluorometer (Thermo Fisher Scientific) and assessed RNA extraction quality via fragment analysis with an ABI 3730 DNA Analyzer (Thermo Fisher Scientific).

We prepared RNAseq libraries from $1 \mu \mathrm{g}$ of total RNA with the NEBNext Poly(A) mRNA Magnetic Isolation Module (NEB) according to the manufacturer protocol. We targeted a 300 450 basepair (bp) fragment size distribution. For cDNA amplification, fifteen PCR cycles were used for all libraries. Presence of a PCR product was visually assessed using an eGel (Thermo

257 Fisher Scientific). Final libraries were quantified with a Qubit 2.0 fluorometer and further 258 assessed for quality, amount of cDNA, and fragment size distribution using a 2100 BioAnalyzer 259 with the High Sensitivity DNA Analysis kit (Agilent). Libraries were then pooled in equal 260 nanomolar concentrations and sequenced on one lane of an Illumina HiSeq4000 with $100 \mathrm{bp}$ 
261 paired-end chemistry by the Roy J. Carver Biotechnology Center at the University of Illinois Urbana-Champaign.

\section{Gene expression analyses and protein annotation}

We assessed raw sequence data quality with fastQC v0.11.4 (Andrews, 2010) and visualized a combined output for all libraries with MultiQC v1.5 (Ewels et al., 2016). Next, we trimmed reads in three successive rounds, all with Trim Galore! v0.4.1 (Krueger, 2015) and default settings except as noted. First, we removed adapter sequences (--illumina --stringency 6). Next, we trimmed for quality and poly-A tails (--quality 20 --stringency 6 --adapter $A\{30\}$-adapter2 $\mathrm{A}\{30\})$. We then trimmed for poly-T tails and discarded reads that had become too short (--stringency 6 --length 50 --adapter T\{30\} --adapter2 T\{30\}). We assessed the quality of

272 the trimmed reads with fastQC v0.11.4. We randomly subsampled one library (Library 3;

273 Control, Mt. St. John) to $80 \%$ of its original amount because its sequencing depth was much

274 higher than the rest of the data set. For this, we used the reformat function of BBTools v37.80

275 (Bushnell, 2014). We removed one library (Library 9; Control, Mt. St. John) from all downstream analyses as it had just 2.6 million reads, far fewer than any other library (see Results).

We mapped reads to the L. tumana reference genome (GenBank \#QKMV00000000.1) with the mitochondrial genome (GenBank \#MH374046; Hotaling et al., 2019c) appended to it. We used HiSat2 v2.1.0 (Pertea et al., 2015) with default settings, first building an index of the reference with the hisat2-build command. To ensure no bias was introduced by differential mapping rates between $L$. tumana and $L$. tetonica samples to the $L$. tumana reference genome, we compared the mean mapping rates for both species with an unpaired $t$-test. Because HiSat2 outputs unsorted SAM files, we converted the output to sorted BAM files with samtools v1.7 (Li et al., 2009).

We generated a gene count matrix for each library with StringTie v1.3.5 (Pertea et al., 2015). We first ran StringTie with the default settings to assemble alignments into potential transcripts without a reference annotation (-G) because none is available for L. tumana. Next, we used the --merge utility to combine library-specific sets of transcripts into a merged, putatively non-redundant set of isoforms. This tool outputs a merged Gene Transfer Format (GTF) file. We then re-ran StringTie using the merged GTF (-G) and the flags -B and -e to enable the output of Ballgown GTF files for the global set of transcripts shared by all samples.

292 Next, we ran the prepDE.py script, also part of the StringTie package, to generate counts 293 matrices for all genes and transcripts identified in the previous steps. 
We performed differential expression analyses using edgeR v3.26.8 (Robinson et al., 2010) in $\mathrm{R}$ version 3.5.2 (R Core Team, 2013). We filtered our data set by requiring transcripts to have more than five total reads and to be present in at least two samples. To visually compare expression variation across groups of interest (i.e., treatments, species, and populations), we used the plotPCA function. After filtering, we identified structure in global gene expression that could not be explained by sample preparation, library size, species, population, or treatment (Figure S3). We removed this unwanted variation with RUVseq v1.18.0 (Risso et al., 2014). Specifically, we used the "in silico empirical" functionality of RUVg where a set of the least differentially expressed genes (DEGs) are identified and used as controls to globally normalize variation in the data set. We used the default trimmed mean of M-values (TMM) method to normalize the data and calculate effective library sizes (Figure S4). Dispersions were estimated using a generalized linear model and a Cox-Reid profile-adjusted likelihood (McCarthy et al., 2012). We identified DEGs with quasi-likelihood F-tests (Lun et al., 2016) which were run using contrasts. We performed DEG identification across three levels of comparison: (1) Within-populations between treatment (collected at their $\mathrm{CT}_{\mathrm{MAX}}$ ) and control (held at $3^{\circ} \mathrm{C}$ ) specimens. (2) Between treatment and control for L. tetonica specimens only (Mt. St. John and Tetonica Pond). (3) Between treatment and control for all specimens. A false discovery rate $(F D R) \leq 0.05$ was used to identify DEGs.

To annotate our data set, we extracted the longest isoform for each gene using the CGAT toolkit and the 'gtf2gtf' function (Sims et al., 2014). We then extracted genes from the file containing the longest isoforms with gffread v.0.9.9 (Trapnell et al., 2012). We performed a blastx search for each gene (E-value: 0.001) against the manually curated and reviewed SwissProt database (Boeckmann et al., 2003; accessed 1 March 2019). Using the results of our blastx search, we annotated genes, retrieved gene ontology (GO) terms, and mapped GO terms using Blast2GO v5.2 (Conesa et al., 2005). We annotated DEGs with the top BLAST hit per transcript. For DEGs without a match in the Swiss-Prot database, we performed two additional searches using online tools: (1) a batch search against the RFAM database (Kalvari et al., 2017; http://rfam.org/search) and (2) a manual blast search (E-value: 0.001) against the automatically annotated and unreviewed TrEMBL database (Boeckmann et al., 2003; http://uniprot.org/blast/).

323 In Blast2GO v5.2, we performed GO term enrichment analyses using the results of our 324 blastx/Swiss-Prot annotations on two test sets with one-tailed Fisher's Exact Tests and FDR $\leq$ 3250.05 after correcting for multiple tests: (1) upregulated genes for $L$. tetonica only and (2) 326 downregulated genes for L. tetonica only. We did not perform GO term enrichment analysis for 327 L. tumana because no DEGs were identified for the representative population we examined 

data set because of redundancy with the L. tetonica analysis (i.e., roughly two-thirds of the same individuals would be included). For enrichment analyses, the complete set of transcripts with BLAST hits were used as the reference set.

To test if stoneflies from more thermally variable environments have muted cellular responses to stress, we identified all genes annotated as heat shock proteins based on BLAST hit descriptions. Next, we sorted these genes by their overall expression [ $\log _{2}$ counts per million (logCPM)] and filtered them to a final set using two criteria: (1) We only included genes expressed at moderate to high levels ( $\geq 4 \log$ CPM) and (2) only retained the most expressed hit (highest mean logCPM) for each unique gene. We did this to prevent any potential bias due to one gene being represented by multiple hits (see Results). Next, we calculated the mean difference in logCPM between treatment and control nymphs for each gene and population. Because the data were not normally distributed $(P$, Shapiro-Wilk $<0.001)$, we compared the distributions of mean differences for each population using a Kruskal-Wallis rank sum test followed by a Dunn test for multiple comparisons. All scripts and commands used in this study are available on GitHub (https://github.com/scotthotaling/Lednia RNAseq).

Results:

Environmental data and species collection

According to the environment criteria described above, we identified one snowmelt-fed stream (Lunch Creek: GNP), two icy seeps (Wind Cave, Mt. St. John; GRTE), two glacier-fed streams (Cloudveil Dome, Skillet Glacier; GRTE), and one alpine pond (Tetonica Pond; GRTE; Table 1). We collected L. tumana from Lunch Creek, Zapada sp. from Wind Cave, and $L$. tetonica from the other four sites (Figure 1, Table 1). Lunch Creek was the warmest $\left(\mathrm{T}_{\mathrm{MEAN}}=\right.$ $\left.6.2^{\circ} \mathrm{C} ; \mathrm{T}_{\mathrm{MAX}}=9.9^{\circ} \mathrm{C}\right)$ and most thermally variable site $\left(\mathrm{T}_{\text {RANGE }}=5.7^{\circ} \mathrm{C}\right.$; Table 1$)$. Cloudveil Dome $\left(\mathrm{T}_{\mathrm{MAX}}=2.1^{\circ} \mathrm{C}\right)$ and Wind Cave $\left(\mathrm{T}_{\mathrm{MAX}}=3.2^{\circ} \mathrm{C}\right)$ were the coldest and least variable sites $\left(\mathrm{T}_{\text {RANGE }} \leq\right.$

$3540.5^{\circ} \mathrm{C}$; Table 1). Icy seeps were the coldest and least thermally variable habitat type overall

$355\left(T_{\text {MAX }}\right.$, icy seeps $=3.9^{\circ} ; T_{\text {RANGE }}$, icy seeps $\left.=1.4^{\circ} \mathrm{C}\right)$. For the two sites with two or more years of

356 available temperature data (2 years, Wind Cave; 3 years, Lunch Creek), thermal differences

357 across years were negligible (Figure S1). 


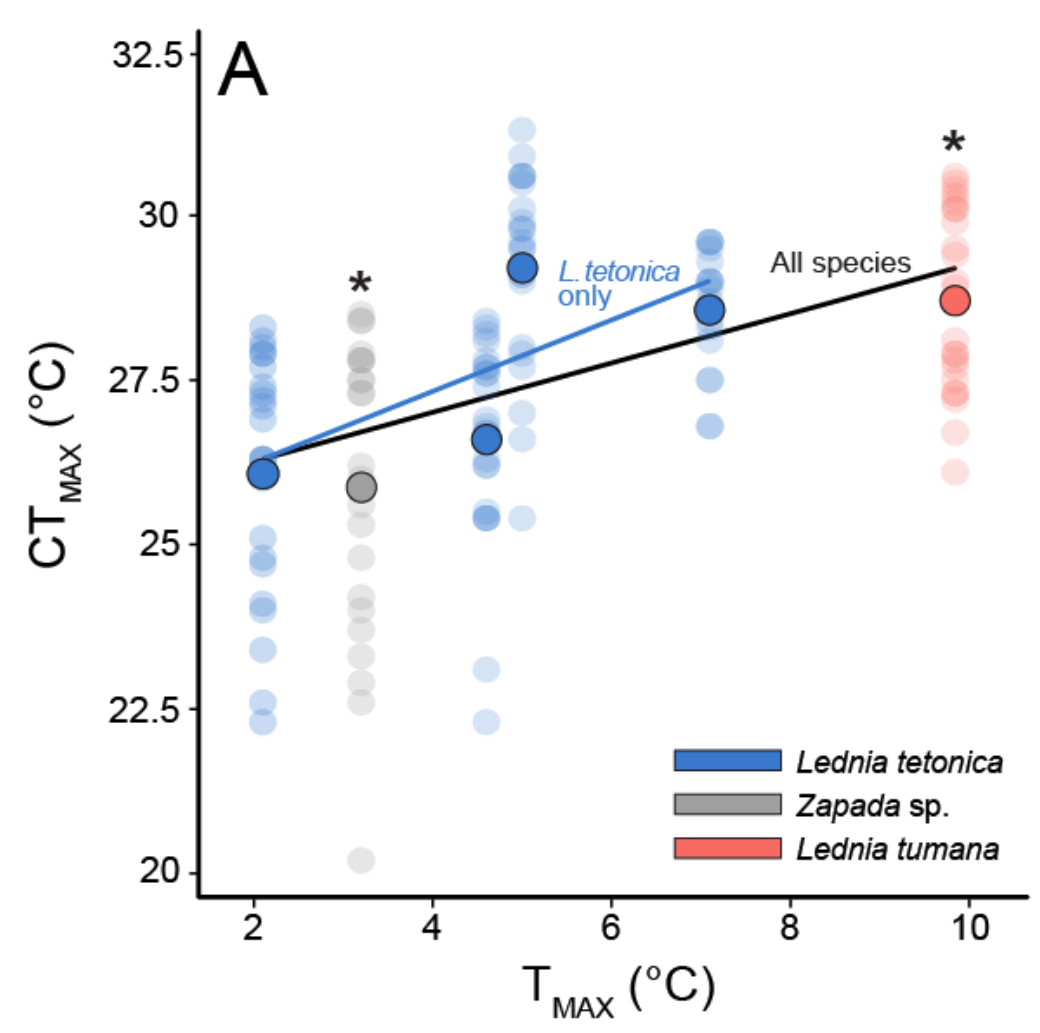

Figure 2: $(A)$ The effect of maximum stream temperature ( $\left.T_{\text {MAX }}\right)$ on critical thermal maximum

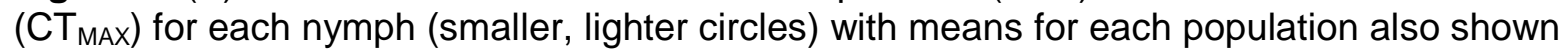
(darker, outlined circles). Asterisks mark the species with only a single population sample (Zapada sp. and L. tumana). Trendlines indicate significant relationships between $\mathrm{T}_{\text {MAX }}$ and $\mathrm{CT}_{\text {MAX }}$ for two separate linear models for $L$. tetonica only (blue line) and for all species (black line). In both analyses, stoneflies from colder streams had lower $\mathrm{CT}_{\text {MAX }}$ values than those from warmer streams. (B) Box plots showing variation in $\mathrm{CT}_{\text {MAX }}$ across species. Black horizontal lines in each box indicate the median with lower and upper bounds of the box representing the lower and upper quartiles of the data, respectively. Whiskers show the maximum and minimum values.

\section{Thermal physiology}

We confirmed that all nymphs survived the $\mathrm{CT}_{\text {MAX }}$ treatment (except for those that were immediately flash frozen for RNAseq and could not be assessed). Body size had no effect on $\mathrm{CT}_{\text {MAX }}$ in the $L$. tetonica $(P=0.58)$ nor all-species analysis $(P=0.28$; Figure $S 5)$. We therefore did not include body size as a covariate in our statistical models. We also found no effect of acclimation period on $\mathrm{CT}_{\mathrm{MAX}}(P=0.41)$. We found differences in $\mathrm{CT}_{\mathrm{MAX}}$ among populations of $L$. tetonica (Figure 2A). Stoneflies inhabiting colder sites exhibited lower $\mathrm{CT}_{\text {MAX }}$ values compared to those from warmer sites $\left(F_{1,85}=26.108, P<0.001\right)$. We observed the lowest $C T_{\text {MAX }}$ for $L$. tetonica in Cloudveil Dome $\left(\mathrm{T}_{\mathrm{MAX}}=2.1^{\circ} \mathrm{C} ; \mathrm{CT}_{\mathrm{MAX}}=26.1^{\circ} \mathrm{C}\right)$, and the highest for $L$. tetonica in Tetonica Pond $\left(\mathrm{T}_{\mathrm{MAX}}=5^{\circ} \mathrm{C} ; \mathrm{CT}_{\mathrm{MAX}}=29.2^{\circ} \mathrm{C}\right)$. We also found a significant positive relationship 
between $\mathrm{T}_{\text {MAX }}$ and $\mathrm{CT}_{\text {MAX }}$ in the all-species analysis which included L. tumana and Zapada sp. $\left(F_{1,132}=39.054, P<0.001\right)$. Although we could not statistically test differences in $\mathrm{CT}_{\text {MAX }}$ among species due to a lack of replicate L. tumana and Zapada sp. populations, our results indicate that $\mathrm{CT}_{\text {MAX }}$ may be highest for L. tumana (Figure 2B). However, this finding may simply be reflective of the only $L$. tumana population sampled also being from Lunch Creek, the warmest

387 site included in this study.

\section{RNA sequencing and annotation}

We generated 368.8 million read pairs for 18 libraries with a mean per sample of 20.6 million \pm 1.9 million (min. = 2.6 million, max. = 39.2 million). After filtering, subsampling of the library with the most reads, and dropping the library with the fewest reads, we retained 354.1 million read pairs. On average, $85.2 \%$ of reads mapped to the $L$. tumana reference genome with L. tumana libraries mapping at a slightly higher rate (mean $89.0 \% \pm 0.5 \%$; $\min .=87.8 \%$, $\max$. = $91.0 \%$ ) than L. tetonica $($ mean $=83.2 \% \pm 0.6 \%$; $\min .=81.0 \%$, max. $=84.5 \% ; P, t$-test $<$ $0.0001)$. However, this difference in mapping rate did not extend to a difference in total reads mapped (mean, $L$. tumana $=19.2$ million, mean $L$. tetonica $=21.7$ million; $P$, $t$-test $=0.42$ ). Raw reads for this study are deposited on the NCBI SRA under BioProject PRJNA587097.

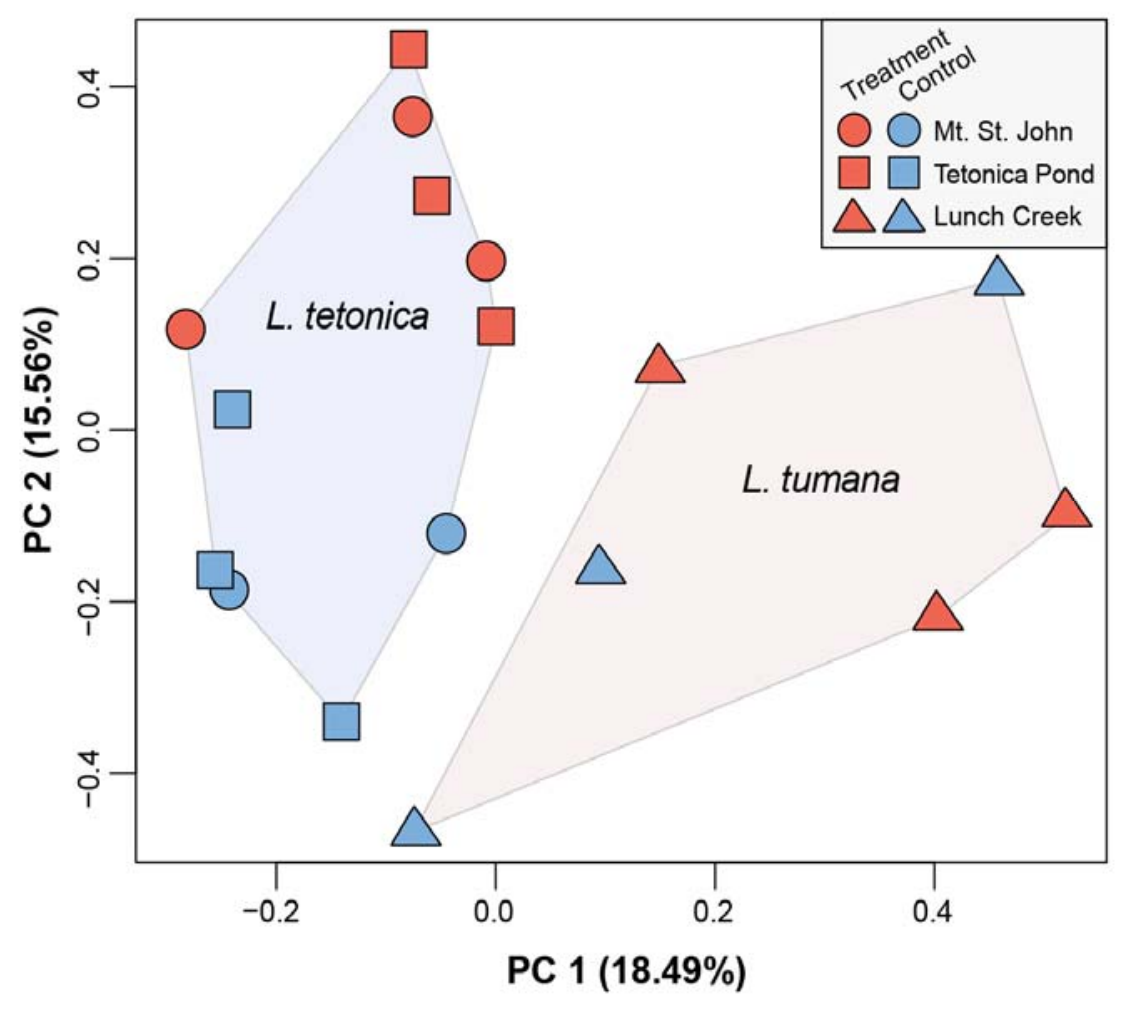


402

403

404

405

406

407

408

409

410

411

412

413

414

415

416

417

418

419

420

421

422

423

424

425

426

427

428

429

430

431

432

433

434

435

436

Figure 3. Global differences in gene expression for stonefly nymphs color-coded by treatment (red, $\mathrm{CT}_{\mathrm{MAX}}$ ) or control (blue, held at $3^{\circ} \mathrm{C}$ ) and grouped by species (colored polygons) and populations (shapes).

\section{Differential expression}

After filtering and processing of the data set, our gene counts matrix contained 52,954 unique entries. We observed global differences in gene expression between $L$. tumana and $L$. tetonica (Figure 3). When L. tumana and L. tetonica were combined (“Lednia"), 80 genes were differentially expressed: 65 upregulated and 15 downregulated in the treatment $\left(\mathrm{CT}_{\mathrm{MAX}}\right)$ versus control group (FDR $\leq 0.05)$. When only L. tetonica populations were considered ("Tetonica"), 71 genes were differentially expressed: 60 upregulated, 11 downregulated. Thirty-four DEGs were shared between groups (32 upregulated, two downregulated). When each population was considered alone, no DEGs were identified (including for Lunch Creek, the only L. tumana population). While we report results for the Lednia and Tetonica data sets above, we focus hereafter on Tetonica because it contains the most statistical power (two populations) with no potential for species-specific bias. Furthermore, due to the fragmented nature of the $L$. tumana genome (contig N50: 4.7 kilobases (kb); 74,445 contigs > 1 kb; Hotaling et al., 2019c), portions of the same gene were likely present on different contigs in the reference. When we assembled transcripts, this manifested as unique transcripts annotated to the same gene. Thus, in many instances (e.g., hexamerins, HEXA; Figures 4, S6), we recovered multiple independent hits to the same gene. While multiple hits may reflect biological reality (e.g., more than one copy of a gene in the genome perhaps reflecting a gene family expansion) we cannot draw such a conclusion. We specify how multiple hits to the same gene were handled where appropriate.

For Tetonica, 46 DEGs (64.8\%) had BLAST hits to the high-quality, manually curated Swiss-Prot database, 32 of which were unique (Table S2). Of the remainder, three (4.2\%) had hits to the RFAM database and nine (12.7\%) had hits to the TrEMBL database. Because the TrEMBL protein database is unreviewed, we only refer to Swiss-Prot/RFAM annotations unless specifically noted. The most upregulated gene [MSTRG.32248; $\log _{2}$ fold change $(\log F C)=15.6$; FDR $=0.015]$ had no annotation to any database (Figure 4). However, the next four mostupregulated genes (logFC = 7-9.1; Figure 4) included $A B C A 3$, which binds ATP, a nucleolysin ( $T I A L 1$ ), and two heat shock proteins HSP70B2 and HSP70A1. The two heat shock proteins were also the most expressed DEGs (logCPM $=8.9$ and 9.3, respectively) after three genes which were all annotated as hexamerins (HEXA; logCPM =9.3-10). Fourteen DEGs had hits to the same apolipophorin gene, $A P L P$, with relatively similar changes in expression (logFC, $A P L P$ =2.1-3.8; Figure S6) and overall expression levels (logCPM, $A P L P=2.2-6.9)$. The three most 
437 downregulated genes did not have BLAST hits to the Swiss-Prot or RFAM databases [logFC = -

4386.6 to -13.7 ; Figure 4], however two of them (MSTRG.1867 and MSTRG.3534) had TrEMBL hits 439 though they were not informative in terms of predicted function (Table S2).

$440 \quad$ Forty-one GO terms were enriched in the upregulated Tetonica data set (Figure S7): 26

441 were classified as being part of a biological process ontology, three were cellular component

442 related, and 11 were linked to molecular function. The top four most significantly enriched GO

443 terms were all lipid-related, including their transport, binding, and localization. Eight of the

444 enriched GO terms (19.5\% overall) were associated with protein folding, and three were linked

445 to chaperone proteins which are commonly associated with physiological stress (Beissinger \&

446 Buchner, 1998). In the same vein, one enriched GO term - "heat shock protein binding"

447 (GO:0031072; FDR = 0.015) - clearly reflected a link to heat stress at the cellular level. No GO

448 terms were enriched for downregulated Tetonica DEGs.

Environmental variability and gene expression

$451 \quad$ Across all populations and species, 38 genes were annotated as heat shock proteins

452 (HSPs). Of these, 12 unique genes were expressed at moderate to high levels ( $\log C P M \geq 4$;

453 Figure S8). We found no support for our hypothesis that stoneflies naturally experiencing higher

454 (and more variable) temperatures exhibit muted cellular stress responses versus those

455 inhabiting colder (and more thermally stable) streams (Figure 5; $P$, Dunn's $\geq 0.66$ ). 
ABCA3: ATP-binding cassette sub-family A member 3

TIAL1: Nucleolysin TIAR

HSP70B2: Heat shock protein $70 \mathrm{~B} 2$ HSP70A1: Heat shock protein $70 \mathrm{~A} 1$

No hit

No hit

AC011: Acyl-CoA Delta(1 PPAF3: Phenoloxidase-activating factor 3 EMC1: ER membrane protein complex subunit 1

No hit

No hit

APLP: Apolipophorins

No hit

No hit

No hit

SQSTM1: Sequestosome-1

LRPPRC: Leucine-rich PPR motif protein, mitochondrial

RPTN: Repetin

No hit

No hit

No hit

No hit

No hit

OGDH-1: 2-oxoglutarate dehydrogenase, mitochondria tRNA

AAEL000794: Clustered mitochondria protein homolog

No hit

HSC70-5: Heat shock $70 \mathrm{kDa}$ protein cognate 5 Ca-transporting ATPase sarcoplasmic/ER type

LON: Lon protease homolog, mitochondria CDC31: Cell division control protein 31

HADHA: Trifunctional enzyme subunit alpha, mitochondria SWS: Neuropathy target esterase sws BARK: Protein bark beetle No hit

REF(2)P: Refractory to sigma $P$ DNAJB12: DnaJ homolog subfamily $B$ member 12 ALDH3A1: Aldehyde dehydrogenase TUFM: Elongation factor Tu, mitochondria EHBP1: EH domain-binding protein 1 BETA-SPEC: Spectrin beta chain CPR: NADPH-cytochrome P450 reductase

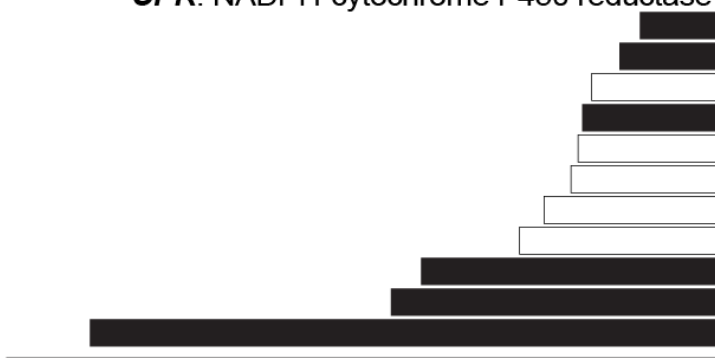

$-10$

\section{Log fold change}

No hit

ARFIP2: Arfaptin-2

No hit

ZMYM1: Zinc finger MYM-type protein 1

PTCHD3: Patched domain-containing protein 3

microRNA mir-252

5 S ribosomal RNA

No hit

No hit

No hit

0

10

Figure 4. Log fold change of Lednia tetonica DEGs (white = BLAST annotated; black = no hit; FDR $\leq 0.05$ ). For annotated genes, only the hits to the Swiss-Prot or RFAM databases with the lowest FDRs are included. The full version of this figure, including any instances of multiple hits to the same protein, is provided in Figure S6. Complete information for each annotation is 462 provided in Table S2. 


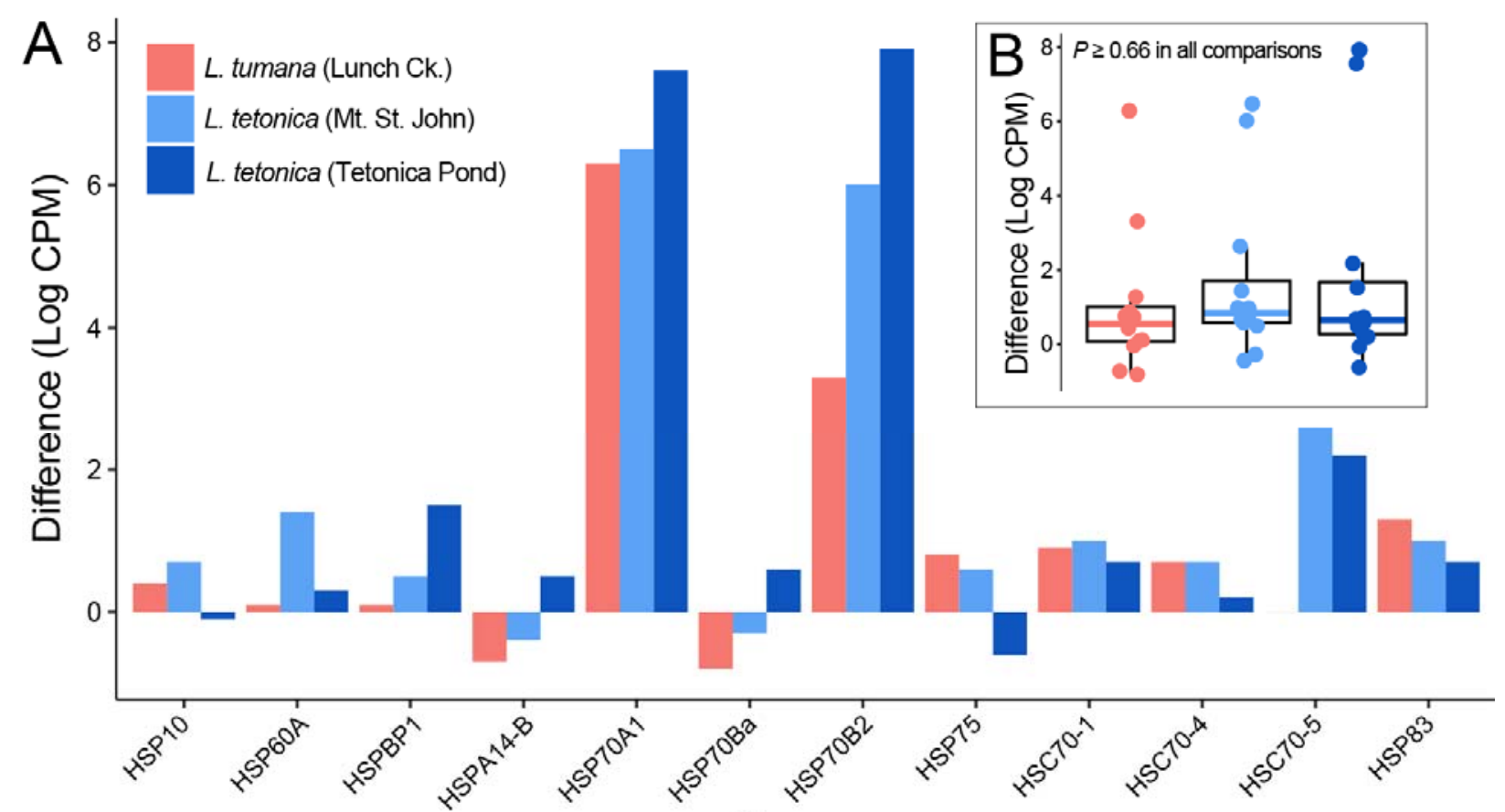

Gene

Figure 5. (A) Mean population-level differences in expression between treatment and control specimens for the 12 most highly expressed, unique HSPs annotated in this study. (B) Distributions of the values in (A) grouped by population. No significant differences were present $(P$, Dunn $<0.05)$.

\section{Discussion:}

As climate change proceeds, headwaters will be dramatically altered by the reduction or loss of meltwater from glaciers and perennial snowfields (Hotaling et al., 2017). However, the physiological limits of high-elevation aquatic insects, a group presumed to be acutely imperiled by climate change, remain largely unknown. In this study, we explored the thermal physiology of high-elevation stoneflies inhabiting the meltwater of rapidly fading glaciers and snowfields in the Rocky Mountains. Our focal species are representative of an entire community that may be at risk of climate-induced extirpation (Giersch et al., 2017, Hotaling et al., 2019a, Tronstad et al., In press), and included L. tumana, a species listed under the U.S. Endangered Species Act due to climate-induced habitat loss (U.S. Fish \& Wildlife Service, 2019). We show that habitat thermal conditions, specifically maximum temperatures, predict upper thermal limits and that nymphs mount a cellular stress response when faced with heat stress. Contrary to our expectations, however, we saw no link between the scale of the stress response and natural conditions that nymphs experience. That is, stoneflies from warmer environments did not exhibit a muted cellular stress response across HSPs versus those from cooler streams. Our results shed new light on thermal tolerance of mountain stoneflies and complement recent cellular perspectives 
on aquatic insect thermal biology (Ebner et al., 2019, Gamboa et al., 2017). Broadly, our findings and those of others (e.g., Ebner et al., 2019, Muhlfeld et al., 2020, Shah et al., 2017b, Treanor et al., 2013), challenge the prevailing notion that aquatic insect larvae living in extremely cold mountain streams cannot survive warming. For Lednia, with the ability to tolerate short-term temperature spikes, we hypothesize that their headwater distributions may be a product of longer-term physiological mechanisms (e.g., the capacity to develop at near freezing temperatures) and biotic factors (e.g., species interactions at lower elevation).

\section{Thermal tolerance}

In mountain systems, thermal tolerance is important to organismal distributions and can help explain the elevation limits of many terrestrial taxa (Andrews, 1998, Brattstrom, 1968, Feder \& Lynch, 1982, Huey \& Webster, 1976, Oyen et al., 2016). Whether thermal tolerance can also explain distributional limits of aquatic taxa is unknown (Polato et al., 2018). We show that species of high-elevation stoneflies in the Rocky Mountains, often described as cold stenotherms that are highly susceptible to warming (e.g., Giersch et al., 2017), can withstand relatively high short-term temperatures (see also Shah et al., 2017b). Although the utility of $\mathrm{CT}_{\text {MAX }}$ has been challenged due to its sensitivity to ramping rates, as well as acclimation and starting temperatures (Rezende et al., 2011, Terblanche et al., 2011), recent arguments in favor of its ecological relevance have also been made (Jørgensen et al., 2019), especially when used in a comparative framework. We contend that $\mathrm{CT}_{\mathrm{MAX}}$ may be uniquely appropriate for mountain stream taxa. Indeed, alpine streams are rapidly warming (e.g., Niedrist \& Füreder, 2020) and in our study system, swift increases in temperature (over a few hours) are common (e.g., Lunch Creek, Figure 1D). With summer streamflows predicted to be reduced under climate change (Huss \& Hock, 2018), baseline temperatures and intraday temperature spikes will both increase as meltwater volume declines and its buffering capacity is lost.

In addition to temperature spikes during certain seasons, average alpine stream

513 temperatures are on the rise (Niedrist \& Füreder, 2020). These higher, but sublethal,

514 temperatures will likely have pervasive negative impacts on high elevation aquatic insects (Shah

515 et al., 2019). For example, long-term thermal tests of $L$. tumana development suggest that

516 mortality during emergence greatly increases around $15{ }^{\circ} \mathrm{C}$ (A.A.S. \& S.H., unpublished data),

517 highlighting how subtle thermal effects on ecological timescales may limit the persistence of $L$.

518 tumana and similar species. Long-term temperature shifts will likely have complex effects on

519 larval energy budgets by differentially altering rates, as well as targets, of energy expenditure 
520 (e.g., resource allocation between somatic growth, maintenance, and reproduction) and energy 521 income from feeding.

$522 \quad$ Simultaneous increases in temperature and reductions in flow may also elevate heat

523 sensitivity in mountain stoneflies by exacerbating a mismatch between oxygen supply and

524 demand. For ectotherms, increasing temperature typically results in increased metabolic rates

525 and greater demand for oxygen (Verberk et al., 2016a). In aquatic habitats, this demand may

526 not be met with adequate oxygen supply, eventually leading to decreased organismal fitness

527 (Pörtner \& Knust, 2007). Evidence for this phenomenon, however, is mixed (Verberk et al.,

528 2016b). With so little known of aquatic insect thermal physiology, it is imperative for future

529 research to address effects of sublethal temperatures and oxygen limitation on thermal

530 tolerance, especially in high-elevation aquatic insects that may encounter a lethal combination

531 of increased temperatures and decreased oxygen from low flows (Jacobsen, 2020).

We observed variation in $\mathrm{CT}_{\mathrm{MAX}}$ among populations of $L$. tetonica, suggesting that local thermal regime may be more important to thermal tolerance than regional thermal regime, and echoing the findings of other recent studies (Gutiérrez-Pesquera et al., 2016, Shah et al., 2017b). This effect of local conditions on thermal tolerance might outweigh differences due to evolutionary history because all species (e.g., Lednia tetonica and Zapada sp.) from cooler streams had lower $\mathrm{CT}_{\text {MAX }}$ than those from warmer streams (Figure 2). Although we cannot determine if thermal variation among populations represents evolved differences, all specimens were held in a common thermal regime for at least 12 hours to limit the effects of previous thermal conditions on $\mathrm{CT}_{\text {MAX }}$ estimates. Regardless of the mechanism, the high-elevation stonefly nymphs included in this study appear poised to cope with short-term warming in

542 streams, although some populations are likely to be more resilient than others (e.g., those 543 experiencing higher present-day maximum temperatures).

$544 \quad$ Given that we focused on larvae in our study, we cannot discern whether other life 545 stages (e.g., eggs or adults) differ in their thermal tolerance. However, we focused on nymphs

546 for three reasons. First, the larval stage is the key developmental period for aquatic insects

547 when the majority of growth and other fitness-related processes (e.g., egg production) occur,

548 and recent modeling suggests that impacts of climate change on species can be greatly

549 underestimated when the larval stage is overlooked (Levy et al., 2015). Second, aquatic insect

550 larvae typically do most of their growing during summer months, when the threat of heat stress 551 is greatest. And, third, egg hatching success in the laboratory was recently shown to be 552 consistently high for mountain stream insects, regardless of rearing temperature, including one 553 treatment $\left(12^{\circ} \mathrm{C}\right)$ that exceeded the highest temperatures the focal midges naturally 
554 experienced (Schütz \& Füreder, 2019). Still, future experiments that link traits (e.g., thermal

555 tolerance) to cellular processes across aquatic insect life cycles will greatly improve our

556 understanding of how sensitivity at key life stages may influence long-term viability of

557 populations.

558

\section{Gene expression}

High-elevation stoneflies residing in cold meltwater-fed streams exhibited a cellular stress response when faced with temperatures at their $\mathrm{CT}_{\mathrm{MAX}}$. The bulk of this response was comprised of upregulated genes and included well-known stress response genes (e.g., HSPs;

563 Lindquist \& Craig, 1988), lesser known but potentially stress-related genes in insects (e.g., 564 APLP, Dassati et al., 2014), and many DEGs that could not be annotated (Figure 4). Three 565 HSPs (HSP70B2, HSP70A1, HSC70-5) were upregulated in nymphs experiencing thermal stress. With well-established roles as cellular protectants, preventing protein denaturation, binding aberrant proteins, and many other stress-induced measures, the upregulation of HSPs was unsurprising (King \& MacRae, 2015). However, given the seemingly psychrophilic lifestyle of Lednia, where individuals develop at temperatures near $0^{\circ} \mathrm{C}$, we expected to see widespread upregulation of HSPs in treatment nymphs. This was not the case. Rather, Lednia appeared to constitutively express many HSPs even at low temperature (Figure S8). This suggests that, contrary to the prevailing view, exposure to low temperatures may actually stress Lednia (see additional discussion below). Similar patterns of constitutive HSP expression have been observed in other cold-tolerant species. For instance, larval caddisflies (Ebner et al., 2019), polar fish (Buckley et al., 2004), and Antarctic grass (Reyes et al., 2003) constitutively express many HSPs, presumably to chaperone proteins at low temperature. The potential for Lednia to be stressed by cold temperatures is further supported by the inability of $L$. tumana nymphs to survive contact with ice (Hotaling et al., In review).

We also observed upregulation of genes with lipid-related functions. Lipids, particularly

580 those in membranes, are extremely sensitive to changes in temperature (Hazel, 1995), and

581 because of their role in key biological processes (e.g., solute diffusion), are important for

582 thermal acclimation and adaptation (Muir et al., 2016, Pernet et al., 2007). Many ectotherms

583 remodel their membrane lipids under thermal stress to maintain fluidity, typically through

584 increases in saturated fatty acids at higher temperatures (Muir et al., 2016). The process of

585 maintaining membrane fluidity in the face of changing temperatures has been termed

586 homeoviscous adaptation (HVA; Sinensky, 1974). The degree of saturation in cuticular lipids of 587 stoneflies varies across life stages, and was speculated to be related to thermal tolerance, 
particularly as it relates to the aquatic versus terrestrial environment (Armold et al., 1969). To our knowledge, the presence of HVA has not been explicitly tested for in any aquatic insect. However, before upregulation of lipid-related genes can be presumed to underlie HVA or similar functional changes in high-elevation stoneflies, alternate explanations about the role of lipids in development must be considered (see below).

While heat stress is presumed to drive the expression patterns we observed, aquatic insects accelerate their development and emerge earlier at warmer temperatures (Nebeker, 1971, Rempel \& Carter, 1987), sometimes even during CT $_{\text {MAX }}$ experiments (A.A.S., personal observation). Thus, some expression changes may be the result of developmental shifts rather than thermal stress directly. When exposed to long-term temperatures above those they naturally experience (e.g., $\geq 15^{\circ} \mathrm{C}$ for $\sim 1$ month), L. tumana nymphs rapidly develop compared to those held at colder temperatures. However, rapidly emerging adults can get stuck and die while shedding their cuticle (S.H. and A.A.S., unpublished data). Some of our results appear more reflective of this developmental shift than heat stress directly. For instance, it has been suggested that $A B C A 3$ is upregulated during insect wing development (Broehan et al., 2013). In our study, high temperatures induced upregulation of $A B C A 3$, perhaps indicating accelerated wing development in preparation for adult emergence. Lipid content in aquatic insects also varies seasonally and tends to peak before metamorphosis, an energetically demanding activity (Cavaletto \& Gardner, 1999). In the caddisfly, Clisoronia magnifica, roughly $80 \%$ of the lipid reserves needed for metamorphosis were used during the last instar (Cargill et al., 1985), which was the same developmental timepoint of the stoneflies included in this study.

The upregulation of HEXA raises similar, albeit more complex, questions. Stoneflies possess two types of hexameric proteins in their hemolymph: hemocyanin $(H C D)$, an oxygencarrying protein, and hexamerins, multi-functional proteins that likely evolved from hemocyanin

612 (Amore et al., 2011, Hagner-Holler et al., 2007). We saw some evidence for the upregulation of $613 H C D$ in heat-stressed stoneflies (Figure S9), perhaps reflecting the physiological challenge of 614 extracting the necessary oxygen from warmer water. However, while hexamerins likely evolved 615 from $H C D$, their function shifted to storage proteins after they lost the ability to bind oxygen 616 (Burmester, 2015, Markl \& Winter, 1989). Present-day hexamerins primarily act as sources of 617 amino acids during non-feeding periods (e.g., emergence, Haunerland, 1996) but may also play 618 a role in cuticle formation (Burmester, 2015, Hagner-Holler et al., 2007), a key stage in aquatic 619 insect emergence. Thus, the upregulation of HEXA may be another cellular indicator of 620 accelerated emergence to escape injurious conditions. 
Mountain stream insects as cold stenotherms: reconsidering a historical paradigm

Aquatic insects living in chronically cold habitats have long been assumed to be coldadapted and therefore intolerant of warming (e.g., Giersch et al., 2017, Jacobsen et al., 2012).

625 This assumption has rarely, if ever, been supported by direct measurements. A potential

626 mismatch between theory and data is particularly important for imperiled species of

627 conservation concern. Lednia tumana is federally endangered under the U.S. Endangered

628 Species Act due to loss of cold, meltwater habitat (U.S. Fish \& Wildlife Service, 2019). As

629 glaciers disappear around the world (Huss \& Hock, 2018), the demise of Lednia and similar

630 species (e.g., Zapada sp.) is presumed to be merely a matter of time (Giersch et al., 2017).

631 While this may be true, alternative hypotheses or threats beyond temperature, at least in the

632 short term, should be considered. Chief among these is the question of realized niche breadth.

633 Factors limiting niche breadth are diverse and may not be directly linked to temperature (e.g.,

634 interspecific competition or food availability, Connell, 1961, Roughgarden, 1974), although

635 thermal sensitivity can certainly play a major role (Gilchrist, 1995). While terrestrial habitats

636 exhibit a wide array of thermal variation, potentially allowing more thermal space for species

637 with similar ecologies to exist in sympatry, the buffering capacity of flowing water may reduce

638 the diversity of thermal niches in streams across similar spatial extents (Shah et al., 2020).

639 Thus, if Lednia exhibit high short-term thermal tolerance, exceeding temperatures they naturally

640 experience, and cellular signatures of stress even at low temperatures (e.g., constitutive

641 expression of HSPs at $3^{\circ} \mathrm{C}$ ), then we hypothesize that the distribution of Lednia and similar

642 species reflects not a requirement for cold conditions but simply a greater tolerance for them

643 versus other species. Rather than being an extreme thermal specialist, Lednia may have

644 evolved a wide thermal niche allowing it to colonize environments free of limiting biological

645 factors. Our hypothesis aligns with previous experimental evidence highlighting the potential for

646 biotic factors beyond temperature to alter alpine stream ecosystems (Khamis et al., 2015) and

647 large-scale ecological data showing the persistence of meltwater-associated biodiversity after

648 deglaciation (Muhlfeld et al., 2020).

649 When considering climate change impacts on mountain stream biodiversity, it is

650 important to distinguish between a species imperiled by rising temperatures, biotic factors, or

651 seemingly by a combination of the two (e.g., Durance \& Ormerod, 2010). At present, the

652 prevailing theory is that a warmer water community will shift uphill and displace coldwater taxa

653 as glaciers and perennial snowfields are lost (Hotaling et al., 2017). This theory assumes that

654 coldwater species (e.g., Lednia) will not be able to tolerate warmer conditions and will be

655 extirpated while lower elevation species simultaneously track their preferred thermal conditions 
upstream. However, if existing headwater communities can tolerate warmer conditions and their

657 lower limits are set by other factors (e.g., competition), then climate change risks for mountain

658 stream communities may be far less generalizable than currently assumed. For instance, if

659 competition at lower elevations limits Lednia distributions then warming temperatures do not

660 guarantee simplistic, binary outcomes of predicted presence or absence. Rather, the future of

661 Lednia and similar taxa may depend upon whether their competitors shift uphill (rather than

662 tolerate warmer conditions in situ), how resources may change, and additional factors that are

663 difficult to predict (see Shah et al., 2020).

\section{Conclusion:}

High-elevation stoneflies in the Rocky Mountains can tolerate higher temperatures in the short-term than those they experience in the wild. When challenged with heat stress, nymphs mount a cellular response that includes upregulation of classic stress response genes (e.g., HSPs) as well as genes that may be involved in developmental transitions from aquatic to terrestrial life stages. Aquatic insects, including L. tumana, develop more rapidly at stable warmer temperatures but also experience higher mortality during emergence (Nebeker, 1971; S.H. and A.A.S., unpublished data). Thus, the potential effects of sublethal warming on performance and other fitness-related traits warrant further investigation. However, in light of our results and similar studies (Ebner et al., 2019, Muhlfeld et al., 2020, Shah et al., 2017b), we challenge the premise that the distribution of mountain stream insects in cold, thermally stable habitats indicates specialized preferences for cold, or evolved physiologies that are only viable in the cold. Rather, the appearance of constitutive expression of many HSPs in Lednia as well as the inability of L. tumana nymphs to survive ice enclosure (Hotaling et al., In review) indicate their contemporary thermal regimes may actually be injurious. Ultimately, if imperiled species

680 like Lednia are not directly threatened by warming temperatures in the near term, then there is clear reason for greater optimism about their future. However, explicit investigations of their development under warmer regimes, rather than simplistic, short-term exposures, are needed in

683 concert with new understanding of how other abiotic factors (e.g., oxygen supply), biotic

684 interactions, and resource availability shape their distributions.

\section{Acknowledgements:}

687 We thank the University of Wyoming-National Park Service (UW-NPS) Research Station for 688 funding. S.H. and J.L.K. were supported by NSF awards \#IOS-1557795 and \#OPP-1906015.

689 A.A.S. was supported by an NSF Postdoctoral Research Fellowship in Biology (DBI-1807694). 
M.E.D. was supported by NSF awards \#DEB-1457659, \#OIA-1826834, and \#EF-1921562. Harold Bergman, Winsor Lowe, Taylor Price, and Lydia Zeglin provided valuable logistic, laboratory, or field assistance. The UW-NPS Research Station provided laboratory space to perform the experiments and the Ghalambor Lab provided insect holding equipment. We performed computational analyses on the Kamiak High Performance Computing Cluster at

695 Washington State University. We thank Christopher Kozakiewicz, Stephen Ormerod, Mark

696 Smithson, and three anonymous reviewers for comments that improved the manuscript. Any

697 use of trade, firm, or product names is for descriptive purposes only and does not imply

698 endorsement by the U.S. Government.

\section{Author contributions:}

S.H. and A.A.S. conceived of the study. S.H., A.A.S., K.L.M., L.M.T., J.J.G., D.S.F., M.E.D., and J.L.K. collected the data. S.H. and A.A.S. analyzed the data and wrote the manuscript with input from K.L.M., H.A.W., M.E.D., and J.L.K. All authors read and approved the final version.

\section{References:}

Amore V, Gaetani B, Puig MA, Fochetti R (2011) New data on the presence of hemocyanin in Plecoptera: Recomposing a puzzle. J Insect Sci, 11, 153.

Andrews RM (1998) Geographic variation in field body temperature of Sceloporus lizards. Journal of Thermal Biology, 23, 329-334.

Andrews S (2010) FastQC: a quality control tool for high throughput sequence data. pp Page, physiology: city ants possess high heat tolerance. PLoS One, 2, e258.

Araújo MB, New M (2007) Ensemble forecasting of species distributions. Trends in Ecology \& Evolution, 22, 42-47.

Armold M, Blomquist G, Jackson L (1969) Cuticular lipids of insects-III. The surface lipids of the aquatic and terrestrial life forms of the big stonefly, Pteronarcys californica Newport.

719 Physiology, 31, 685-692.

720 Bálint M, Domisch S, Engelhardt C et al. (2011) Cryptic biodiversity loss linked to global climate change. Nature Climate Change, 1, 313.

Beissinger M, Buchner J (1998) How chaperones fold proteins. Journal of Biological Chemistry, 379, 245-259. 
724

725

726

727

728

729

730

731

732

733

734

735

736

737

738

739

740

741

742

743

744

745

746

747

748

749

750

751

752

753

754

755

756

Boeckmann B, Bairoch A, Apweiler R et al. (2003) The SWISS-PROT protein knowledgebase and its supplement TrEMBL in 2003. Nucleic Acids Res, 31, 365-370.

Brattstrom BH (1968) Thermal acclimation in anuran amphibians as a function of latitude and altitude. J Comparative Biochemistry \& Physiology, 24, 93-111.

Broehan G, Kroeger T, Lorenzen M, Merzendorfer H (2013) Functional analysis of the ATPbinding cassette $(\mathrm{ABC})$ transporter gene family of Tribolium castaneum. BMC Genomics, 14, 6.

Buckley BA, Place SP, Hofmann GE (2004) Regulation of heat shock genes in isolated hepatocytes from an Antarctic fish, Trematomus bernacchii. Journal of Experimental Biology, 207, 3649-3656.

Burmester T (2015) Expression and evolution of hexamerins from the tobacco hornworm, Manduca sexta, and other Lepidoptera. Insect Biochemistry and Molecular Biology, 62, 226-234.

Bushnell B (2014) BBTools software package.

Cargill AS, Cummins KW, Hanson BJ, Lowry RR (1985) The role of lipids, fungi, and temperature in the nutrition of a shredder caddisfly, Clistoronia magnifica. Freshwater Invertebrate Biology, 4, 64-78.

Cavaletto JF, Gardner WS (1999) Seasonal dynamics of lipids in freshwater benthic invertebrates. In: Lipids in freshwater ecosystems. pp Page., Springer.

Chown SL, Hoffmann AA, Kristensen TN, Angilletta Jr MJ, Stenseth NC, Pertoldi C (2010) Adapting to climate change: a perspective from evolutionary physiology. Climate Research, 43, 3-15.

Conesa A, Götz S, García-Gómez JM, Terol J, Talón M, Robles M (2005) Blast2GO: a universal tool for annotation, visualization and analysis in functional genomics research. Bioinformatics, 21, 3674-3676.

Connell JH (1961) The influence of interspecific competition and other factors on the distribution of the barnacle Chthamalus stellatus. Ecology, 42, 710-723.

Dassati S, Waldner A, Schweigreiter R (2014) Apolipoprotein D takes center stage in the stress response of the aging and degenerative brain. Neurobiol Aging, 35, 1632-1642.

Durance I, Ormerod SJ (2010) Evidence for the role of climate in the local extinction of a coolwater triclad. Journal of the North American Benthological Society, 29, 1367-1378.

Ebner JN, Ritz D, Von Fumetti S (2019) Comparative proteomics of stenotopic caddisfly Crunoecia irrorata identifies acclimation strategies to warming. Mol Ecol, 28, 4453-4469. 
Ewels P, Magnusson M, Lundin S, Käller M (2016) MultiQC: summarize analysis results for multiple tools and samples in a single report. Bioinformatics, 32, 3047-3048.

Feder ME, Lynch JF (1982) Effects of latitude, season, elevation, and microhabitat on field body temperatures of neotropical and temperate zone salamanders. Ecology, 63, 1657-1664.

Finn DS, Khamis K, Milner AM (2013) Loss of small glaciers will diminish beta diversity in Pyrenean streams at two levels of biological organization. Global Ecology and Biogeography, 22, 40-51.

Gamboa M, Tsuchiya MC, Matsumoto S, Iwata H, Watanabe K (2017) Differences in protein expression among five species of stream stonefly (Plecoptera) along a latitudinal gradient in Japan. Archives of Insect Biochemistry \& Physiology, 96, e21422.

Giersch JJ, Hotaling S, Kovach RP, Jones LA, Muhlfeld CC (2017) Climate-induced glacier and snow loss imperils alpine stream insects. Global Change Biology, 23, 2577-2589.

Giersch JJ, Jordan S, Luikart G, Jones LA, Hauer FR, Muhlfeld CC (2015) Climate-induced range contraction of a rare alpine aquatic invertebrate. Freshwater Science, 34, 53-65.

Gilchrist GW (1995) Specialists and generalists in changing environments. I. Fitness landscapes of thermal sensitivity. Am Nat, 146, 252-270.

Gutiérrez-Pesquera LM, Tejedo M, Olalla-Tárraga M, Duarte H, Nicieza A, Solé M (2016) Testing the climate variability hypothesis in thermal tolerance limits of tropical and temperate tadpoles. Journal of Biogeography, 43, 1166-1178.

Hagner-Holler S, Pick C, Girgenrath S, Marden JH, Burmester T (2007) Diversity of stonefly hexamerins and implication for the evolution of insect storage proteins. Insect Biochemistry and Molecular Biology, 37, 1064-1074.

Haunerland N (1996) Insect storage proteins: gene families and receptors. Insect Biochemistry \& Molecular Biology, 26, 755-765.

Hazel JR (1995) Thermal adaptation in biological membranes: is homeoviscous adaptation the explanation? Annual Review of Physiology, 57, 19-42.

Healy TM, Brennan RS, Whitehead A, Schulte PM (2018) Tolerance traits related to climate change resilience are independent and polygenic. Global Change Biology, 24, 53485360.

Hotaling S, Foley ME, Zeglin LH et al. (2019a) Microbial assemblages reflect environmental heterogeneity in alpine streams. Global Change Biology, 25, 2576-2590. 
Hotaling S, Giersch JJ, Finn DS et al. (2019b) Congruent population genetic structure but differing depths of divergence for three alpine stoneflies with similar ecology, geographic distributions, and climate change threats. Freshwater Biology, 64, 335-347.

Hotaling S, Kelley JL, Weisrock DW (2019c) Nuclear and mitochondrial genomic resources for the meltwater stonefly (Plecoptera: Nemouridae), Lednia tumana (Ricker, 1952). Aquatic Insects, 1-8.

Hotaling S, Shah AA, Dillon ME, Giersch JJ, Tronstad LM, Finn DS, Kelley JL (In review) Cold physiology of mountain stoneflies (Plecoptera: Nemouridae): Insights from the high Rocky Mountains. Western North American Naturalist.

Huey RB, Webster TP (1976) Thermal biology of Anolis lizards in a complex fauna: the Christatellus group on Puerto Rico. Ecology, 57, 985-994.

Huss M, Hock R (2018) Global-scale hydrological response to future glacier mass loss. Nature Climate Change, 8, 135.

Isaak DJ, Young MK, Nagel DE, Horan DL, Groce MC (2015) The cold-water climate shield: delineating refugia for preserving salmonid fishes through the 21st century. Global Change Biology, 21, 2540-2553.

Jacobsen D (2020) The dilemma of altitudinal shifts: caught between high temperature and low oxygen. Frontiers in Ecology and the Environment.

Jacobsen D, Milner AM, Brown LE, Dangles O (2012) Biodiversity under threat in glacier-fed river systems. Nature Climate Change, 2, 361-364.

Jones LA, Muhlfeld CC, Marshall LA, Mcglynn BL, Kershner JL (2014) Estimating Thermal Regimes of Bull Trout and Assessing the Potential Effects of Climate Warming on Critical Habitats. River Research and Applications, 30, 204-216. Loss of genetic diversity and increased subdivision in an endemic alpine stonefly threatened by climate change. PLoS One, 11, e0157386.

Jørgensen LB, Malte H, Overgaard J (2019) How to assess Drosophila heat tolerance: unifying static and dynamic tolerance assays to predict heat distribution limits. Functional Ecology, 33, 629-642.

Kalvari I, Argasinska J, Quinones-Olvera N et al. (2017) Rfam 13.0: shifting to a genome-centric resource for non-coding RNA families. Nucleic Acids Res, 46, D335-D342.

Kearney M, Shine R, Porter WP (2009) The potential for behavioral thermoregulation to buffer "cold-blooded" animals against climate warming. Proceedings of the National Academy of Sciences, 106, 3835-3840. 
Khamis K, Brown LE, Hannah DM, Milner AM (2015) Experimental evidence that predator range expansion modifies alpine stream community structure. Freshwater Science, 34, 66-80.

King AM, Macrae TH (2015) Insect heat shock proteins during stress and diapause. Annual Review of Entomology, 60, 59-75.

Krueger F (2015) Trim Galore!: a wrapper tool around Cutadapt and FastQC to consistently apply quality and adapter trimming to FastQ files. Babraham Bioinformatics, Cambridge, United Kingdom. pp Page.

Levy O, Buckley LB, Keitt TH, Smith CD, Boateng KO, Kumar DS, Angilletta Jr MJ (2015) Resolving the life cycle alters expected impacts of climate change. Proceedings of the Royal Society B: Biological Sciences, 282, 20150837.

Li H, Handsaker B, Wysoker A et al. (2009) The sequence alignment/map format and SAMtools.

Lindquist S, Craig E (1988) The heat-shock proteins. Annual Review of Genetics, 22, 631-677.

Lister BC, Garcia A (2018) Climate-driven declines in arthropod abundance restructure a rainforest food web. Proceedings of the National Academy of Sciences, 115, E10397E10406.

Markl J, Winter S (1989) Subunit-specific monoclonal antibodies to tarantula hemocyanin, and a common epitope shared with calliphorin. Journal of Comparative Physiology B, 159, 139-151.

Mccarthy DJ, Chen Y, Smyth GK (2012) Differential expression analysis of multifactor RNA-Seq experiments with respect to biological variation. Nucleic Acids Res, 40, 4288-4297.

Muhlfeld CC, Cline TJ, Giersch JJ, Peitzsch E, Florentine C, Jacobsen D, Hotaling S (2020) Specialized meltwater biodiversity persists desite widespread deglaciation. Proceedings of the National Academy of Sciences.

Nebeker AV (1971) Effect of water temperature on nymphal feeding rate, emergence, and adult longevity of the stonefly Pteronarcys dorsata. Journal of the Kansas Entomological Society, 21-26. 
Niedrist GH, Füreder L (2020) Real-time warming of alpine streams: (re)defining invertebrates' temperature preferences. River Research and Applications.

Oyen KJ, Giri S, Dillon ME (2016) Altitudinal variation in bumble bee (Bombus) critical thermal limits. Journal of Thermal Biology, 59, 52-57.

Peckarsky BL, Mcintosh AR, Horn SC et al. (2014) Characterizing disturbance regimes of mountain streams. Freshwater Science, 33, 716-730.

Pernet F, Tremblay R, Comeau L, Guderley H (2007) Temperature adaptation in two bivalve species from different thermal habitats: energetics and remodelling of membrane lipids. Journal of Experimental Biology, 210, 2999-3014.

Pertea M, Pertea GM, Antonescu CM, Chang T-C, Mendell JT, Salzberg SL (2015) StringTie enables improved reconstruction of a transcriptome from RNA-seq reads. Nature

Pörtner HO, Knust R (2007) Climate change affects marine fishes through the oxygen limitation of thermal tolerance. Science, 315, 95-97.

Pörtner HO, Peck L, Somero G (2007) Thermal limits and adaptation in marine Antarctic ectotherms: an integrative view. Philos Trans R Soc Lond B Biol Sci, 362, 2233-2258.

R Core Team (2013) R: A language and environment for statistical computing.

Rempel RS, Carter JC (1987) Temperature influences on adult size, development, and reproductive potential of aquatic Diptera. Canadian Journal of Fisheries \& Aquatic Sciences, 44, 1743-1752.

Reyes MA, Corcuera LJ, Cardemil L (2003) Accumulation of HSP70 in Deschampsia antarctica Desv. leaves under thermal stress. Antarctic Science, 15, 345-352.

Rezende EL, Tejedo M, Santos M (2011) Estimating the adaptive potential of critical thermal limits: methodological problems and evolutionary implications. Functional Ecology, 25, 111-121.

Risso D, Ngai J, Speed TP, Dudoit S (2014) Normalization of RNA-seq data using factor analysis of control genes or samples. Nature Biotechnology, 32, 896.

Robinson MD, Mccarthy DJ, Smyth GK (2010) edgeR: a Bioconductor package for differential expression analysis of digital gene expression data. Bioinformatics, 26, 139-140.

Roughgarden J (1974) Niche width: biogeographic patterns among Anolis lizard populations. Am Nat, 108, 429-442. 
Sánchez-Bayo F, Wyckhuys KA (2019) Worldwide decline of the entomofauna: A review of its drivers. Biological Conservation, 232, 8-27.

Schütz SA, Füreder L (2019) Egg development and hatching success in alpine chironomids. Freshwater Biology, 64, 685-696.

Seebacher F, White CR, Franklin CE (2015) Physiological plasticity increases resilience of ectothermic animals to climate change. Nature Climate Change, 5, 61.

Shah AA, Dillon ME, Hotaling S, Woods HA (2020) High elevation insect communities face shifting ecological and evolutionary landscapes. Current Opinion in Insect Science.

Shah AA, Funk WC, Ghalambor CK (2017a) Thermal acclimation ability varies in temperate and tropical aquatic insects from different elevations. J Integrative Comparative Biology, 57,

Shah AA, Woods HA, Havird JC et al. (2019) Temperature-dependence of metabolic rate in tropical and temperate aquatic insects: support for the Climate Variability Hypothesis in mayflies but not stoneflies. bioRxiv.

Sims D, llott NE, Sansom SN et al. (2014) CGAT: computational genomics analysis toolkit. Bioinformatics, 30, 1290-1291.

Sinensky M (1974) Homeoviscous adaptation-a homeostatic process that regulates the viscosity of membrane lipids in Escherichia coli. Proceedings of the National Academy of Sciences, 71, 522-525.

Terblanche JS, Hoffmann AA, Mitchell KA, Rako L, Le Roux PC, Chown SL (2011) Ecologically relevant measures of tolerance to potentially lethal temperatures. J Exp Biol, 214, 37133725.

916 Trapnell C, Roberts A, Goff L et al. (2012) Differential gene and transcript expression analysis of 917 RNA-seq experiments with TopHat and Cufflinks. Nature Protocols, 7, 562.

918 Treanor HB, Giersch JJ, Kappenman KM, Muhlfeld CC, Webb MaH (2013) Thermal tolerance of 919 meltwater stoneflyLednia tumananymphs from an alpine stream in Waterton-Glacier 920 International Peace Park, Montana, USA. Freshwater Science, 32, 597-605.

921 Tronstad LM, Hotaling S, Giersch JJ, Wilmot OJ, Finn DS (In press) Headwater streams fed by 922 subterranean ice: potential climate refugia for mountain communities? Western North 923 American Naturalist. 
924 U.S. Fish \& Wildlife Service (2019) Endangered and Threatened Wildlife and Plants:

$925 \quad$ Threatened Species Status for Meltwater Lednian Stonefly and Western Glacier Stonefly

926 with a Section 4(d) Rule. Federal Register, 84, 64210-64227.

927 Urban MC, Bocedi G, Hendry AP et al. (2016) Improving the forecast for biodiversity under

$928 \quad$ climate change. Science, 353, aad8466.

929 Verberk WC, Durance I, Vaughan IP, Ormerod SJ (2016a) Field and laboratory studies reveal

930 interacting effects of stream oxygenation and warming on aquatic ectotherms. Global

$931 \quad$ Change Biology, 22, 1769-1778.

932 Verberk WC, Overgaard J, Ern R, Bayley M, Wang T, Boardman L, Terblanche JS (2016b)

933 Does oxygen limit thermal tolerance in arthropods? A critical review of current evidence.

934 Comparative Biochemistry \& Physiology Part A: Molecular Integrative Physiology, 192,

935 64-78.

936 Ward J (1994) Ecology of alpine streams. Freshwater Biology, 32, 277-294.

937 